\title{
REMOVAL OF CADMIUM IONS FROM SYNTHETIC WASTEWATER BY USING Pennisetum purpureum (ELEPHANT GRASS) AS LOW COST BIODEGRADABLE ADSORBENT (BIOSORBENT)
}

\author{
LING SHING YUN AND ASMADI ALI* \\ School of Ocean Engineering, Universiti Malaysia Terengganu, \\ 21030 Kula Nerus, Terengganu, Malaysia
}

"Corresponding Author: asmadi@umt.edu.my

\begin{abstract}
At present, heavy metal pollution is a major environmental concern and the adsorption technique is a potent method for removal of these heavy metals from wastewater. Activated carbon is one of the best adsorbents for metal ions removal but it is sometimes restricted due to high cost and problems with regeneration hamper large scale application. Low cost adsorbent is alternatively being introduced to replace activated carbon since it is available in large quantity, renewable and inexpensive. Hence, Pennisetum purpureum (elephant grass) was investigated for its potential in cadmium ions removal. The adsorbent was characterized by Fourier Transforms Infrared Spectroscopy (FT-IR), Scanning Electron Microscopy (SEM), Brunauer-Emmett-Teller (BET) and Barrett-Joyner-Halenda (BJH) analyses. The effects of $\mathrm{pH}$ (1 to 5), initial metal ion concentration (5 to $25 \mathrm{mg} / \mathrm{L}$ ), contact time (10 to 60 minutes) and adsorbent dosage ( 0.2 to $1.0 \mathrm{~g}$ ) on cadmium ions removal were conducted by batch adsorption experiments. In this study, the FT-IR results demonstrated that the functional groups for untreated and nitric acid-treated $P$. purpureum mainly consisted of carbonyl, carboxyl, hydroxyl and amine groups which are able to bind with positively charged cadmium ions. SEM micrographs have proven that nitric acid modification would remove the surface impurities of $P$. purpureum, which increased the surface roughness, produced deep, open pores and better pore size distribution. From the BET and BJH analyses, the treated $P$. purpureum was mesoporous, had larger surface area and pore volume compared to untreated $P$. purpureum. The best $\mathrm{pH}$, adsorbent dosage and contact time were $\mathrm{pH}$ $4,0.6 \mathrm{~g}$ and 30 minutes, respectively. The highest removal percentage of cadmium ions for both untreated and treated $P$. purpureum were $92 \%$ and $98 \%$ correspondingly. The results shown strengthened the fact that both biosorbents have great potential in cadmium ions removal.
\end{abstract}

Keywords: Undergraduate research, adsorption, low cost adsorbent, cadmium, Pennisetum purpureum

\section{Introduction}

The presence of heavy metals in wastewater is a major hazard to surface water, animals and human health. Heavy metals are produced by electroplating, dyeing, metal finishing and chemical processing industries. Moreover, heavy metals are non-biodegradable and highly soluble in aquatic environment. They can be absorbed by living organisms and may bio-accumulate in the human body if they enter the food chain. Heavy metals can cause serious health problems if consumed beyond the permitted concentration (Babel \& Kurniawan, 2004). Therefore, it is necessary to treat metal-contaminated wastewater prior to its discharge to the environment.

One of the non-essential metals is Cadmium $(\mathrm{Cd})$, which is poisonous for plants, humans and animals (Raja et al., 2009). It is a soft, silver-white metal which does not have a defined taste or odor. Location of the periodic table is in group IIB. Atomic number is 48 and atomic mass is
112.411. The most severe disease caused by cadmium poisoning is "Itai-Itai" disease in Japan. Cd toxicity is associated with pulmonary, renal, hepatic, skeletal, reproductive and cardiovascular dysfunctions (Hong et al., 2004; Koyu et al., 2006; Tellez-Plaza et al., 2008). It is also classified as a group I human carcinogen by the International Agency for Research on Cancer (IARC, 1993). Conventional treatments for cadmium ions removal such as chemical precipitation, ion exchange, oxidation and reduction, filtration and membrane separation have significant disadvantages such as incomplete removal, high-energy requirements, and production of toxic sludge (Barakat, 2011). Of all the methods, adsorption has been found to be effective and low cost (Venkatesan \& Senthilnathan, 2013). Although commercial activated carbon is widely used for the removal of heavy metals, it is sometimes restricted for industrial use due to its high cost and industries following different strategies on disposal of end-of-life sorbent. This happens mainly in developing countries and under developing countries. Hence, there is 
a need to derive a low cost adsorbent for the removal of cadmium from wastewater. Thus, in this study $P$. purpureum was selected for treating cadmium in synthetic wastewater in order to explore its potential as a low cost biosorbent at its promising characteristics and performance in control adsorption batch experiments.

\section{Materials and Methods \\ Biomass Pre-treatment}

P. purpureum was collected from around Gong Badak, Kuala Nerus, Terengganu. The raw P. purpureum was washed with distilled water to remove all the impurities. The sample was bottomed with aluminum foil and put into universal oven for drying purpose at $105^{\circ} \mathrm{C}$ for 24 hours until a constant mass was achieved. The dried $P$. purpureum was cut into pieces of approximately $0.5 \mathrm{~cm}$ (Babarinde \& Babalola, 2010). Zip lock bags were prepared to store the untreated and treated biosorbents, labeled clearly and placed into desiccator for future use. Similar procedure was followed for the preparation of treated Pennisetum purpureum. $10 \mathrm{~g}$ of the untreated $P$. purpureum was immersed into $100 \mathrm{~mL}$ of $2 \mathrm{M}$ nitric acid $\left(\mathrm{HNO}_{3}\right)$ solution, agitated in a water bath shaker at 200rpm for 6 hours at room temperature (Raoul et al., 2016). The acid solution was filtered off, washed with distilled water and soaked in $0.1 \mathrm{M}$ sodium hydroxide $(\mathrm{NaOH})$ to remove residual acid. The solution was filtered off and washed with distilled water again, then oven-dried at $105^{\circ} \mathrm{C}$ for 24 hours. Both biosorbents were prepared and kept dry until the time of usage.

\section{Reagents and Equipment}

All the chemical reagents used in this study are analytical grade. $1000 \mathrm{mg} / \mathrm{L}$ of cadmium nitrate tetrahydrate $\left(\mathrm{Cd}\left(\mathrm{NO}_{3}\right)_{2} \cdot 4 \mathrm{H}_{2} \mathrm{O}\right)$ stock solution was prepared by dissolving requisite amount of powder in 1 litre of deionized water. The stock solution was diluted to required concentrations, followed by $\mathrm{pH}$ adjustment with $0.1 \mathrm{M}$ $\mathrm{HNO}_{3}$ and $0.1 \mathrm{M} \mathrm{NaOH}$, measured by $\mathrm{pH}$ meter. The spectrophotometric determination of cadmium ion was done by adding $1 \mathrm{~mL}$ of sample with adjusted $\mathrm{pH}$ to the range of $\mathrm{pH} 5.5$ to $\mathrm{pH} 6.1$, followed by $1 \mathrm{~mL}$ of $1.39 \times 10^{-}$ ${ }^{1} \mathrm{M}$ Alizarin red $\mathrm{S}\left(\mathrm{C}_{14} \mathrm{H}_{8} \mathrm{O}_{7} \mathrm{~S}\right)$ in a $10 \mathrm{~mL}$ measuring cylinder. Deionized water was added to mark and mixed well. This is because Alizarin red S reacts in slightly acidic solution with cadmium to give a deep greenish yellow chelate which has a maximum absorption at $422 \mathrm{~nm}$ (Ullah \& Haque, 2010). UV-Vis spectrophotometer was used for residual metal ions analysis after each biosorption process at $422 \mathrm{~nm}$.

For the characterization of both biosorbents, Fourier Transform Infrared Spectroscopy (FT-IR) was used to determine the surface functional groups for both untreated and treated $P$. purpureum which are responsible for bonding between the $P$. purpureum and cadmium ions. The spectral were recorded ranging from 4000-400 $\mathrm{cm}^{-1}$. Scanning Electron Microscopy (SEM) was used to characterize the surface morphology and fundamental physical properties of the adsorbent materials. The analysis was conducted at 1000 times magnification with shown SEM micrograph. The specific surface area and pore volume were determined by using nitrogen adsorptiondesorption isotherm properties. The analysis was carried out by using Micromeritics ASAP 2000, available in Central Laboratory, UMT.

\section{Batch Biosorption Procedure}

The biosorption was carried out by using batch method to investigate the effect of $\mathrm{pH}$, contact time, initial metal ion concentration and adsorbent dosage on the biosorption of cadmium ions. For the fixed variables at the beginning of the experiment, $0.5 \mathrm{~g}$ biosorbent was contacted with $25 \mathrm{~mL}$ of $20 \mathrm{mg} / \mathrm{L}$ cadmium solution in a sealed $100 \mathrm{~mL}$ conical flask and agitated vigorously by using water bath shaker. The shake speed was kept constant at $250 \mathrm{rpm}$ for 30 minutes. The variables could be changed based on the best condition obtained. The $\mathrm{pH}$ of the solution was adjusted with $1 \mathrm{M} \mathrm{HCl}$ and $1 \mathrm{M} \mathrm{NaOH}$ in the range of 1 to 5 . The sealed flasks were agitated for contact time intervals of 10 minutes to 60 minutes. The influence of initial metal ion concentration ( 5 to $25 \mathrm{mg} / \mathrm{L})$ and adsorbent dosage $(0.2 \mathrm{~g}$ to $1.0 \mathrm{~g}$ ) was also investigated in this study. Samples were collected from the flasks and the residual cadmium ion concentration in each flask was analyzed. The suspensions were filtered through Whatman filter paper and the supernatants were analyzed by measuring absorbance at maximum wavelength of $422 \mathrm{~nm}$ using UV-Vis Spectrophotometer. The biosorption experiments were repeated in triplicate to reduce any possible random errors. The percentages of removal of cadmium ions by both biosorbents were calculated using Equation (1)

Where

$$
\text { Percentage of removal }(\%)=\frac{C_{o}-C}{C_{o}} \times 100 \%
$$

$C_{o}=$ Initial cadmium ions concentration, $\mathrm{mg} / \mathrm{L}$

$\mathrm{C}=$ Final concentration of the solution after experiment, $\mathrm{mg} / \mathrm{L}$ 


\section{Results and Discussion Fourier Transform Infrared Spectrocopy (FT-IR)}

FT-IR spectra analysis was used mainly to identify the existence of available functional groups (carboxyl, hydroxyl and amine groups) that were capable of adsorbing cadmium ions (Qiao et al., 2014). FT-IR spectra of untreated and treated $P$. purpureum are shown in Figure 1 and Figure 2 respectively. The peaks were observed at $3375.64 \mathrm{~cm}^{-1}$ and $3275.67 \mathrm{~cm}^{-1}$ in untreated and treated biosorbents respectively, which indicated the presence of intermolecular hydrogen bonding with functional groups of $\mathrm{O}-\mathrm{H}$ stretching and $\mathrm{N}-\mathrm{H}$ stretching (Kamarullah et al., 2015). The FT-IR peaks were also observed at $1644.08 \mathrm{~cm}$ 1 and $1656.73 \mathrm{~cm}^{-1}$ in untreated and treated biosorbent accordingly. At this range, the $\mathrm{C}=\mathrm{C}$ stretching and $\mathrm{C}=\mathrm{N}$ stretching from alkenes and imine or oxime group were identified. However, the $\mathrm{C}=\mathrm{C}$ bending of untreated biosorbent was identified at wave number of $803.94 \mathrm{~cm}^{-1}$. Besides that, C-O stretch and C-N stretch were discovered for both untreated and treated biosorbent, at wave number of $1054.28 \mathrm{~cm}^{-1}$ and $1055.42 \mathrm{~cm}^{-1}$ correspondingly.
Moreover, C-H stretching from alkanes group was identified and $\mathrm{sp}^{3} \mathrm{C}-\mathrm{H}$ absorption was observed for both untreated and treated biosorbents. The FT-IR bands at 2894 - $2917 \mathrm{~cm}^{-1}$ corresponded to lignin composition. In short, both untreated and treated biosorbents consist of functional groups with lone pairs of electrons which are able to attract and bind with positively charged cadmium ions. It can be suggested that $P$. purpureum is basically composed of lignin, cellulose and hemicelluloses structure, and all these components contribute as active sites for adsorption of metal ions. The treated biosorbent shifted to higher absorption frequency values than untreated biosorbent, which denoted that treated biosorbent has a higher adsorption capacity than untreated biosorbent. The detailed categorization of wave number corresponded to type of vibration and functional group as shown in Table 1. The presence of carboxyl, carbonyl, hydroxyl and amine functional groups on biosorption of cadmium ions mainly contributes to ion exchange, physical adsorption, electrostatic attraction and complexation mechanisms (Javanbakht et al., 2014).

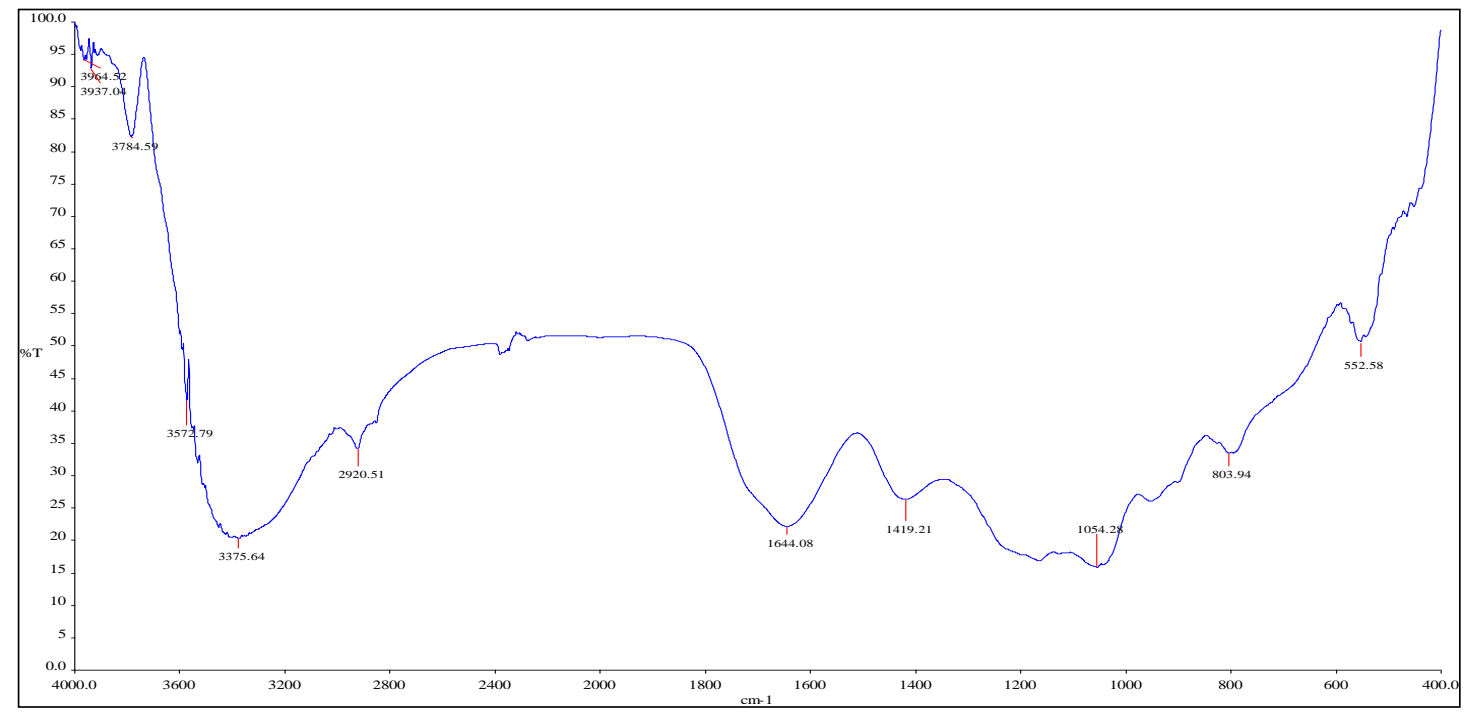

Figure 1: FT-IR spectrum of untreated $P$. purpureum. 


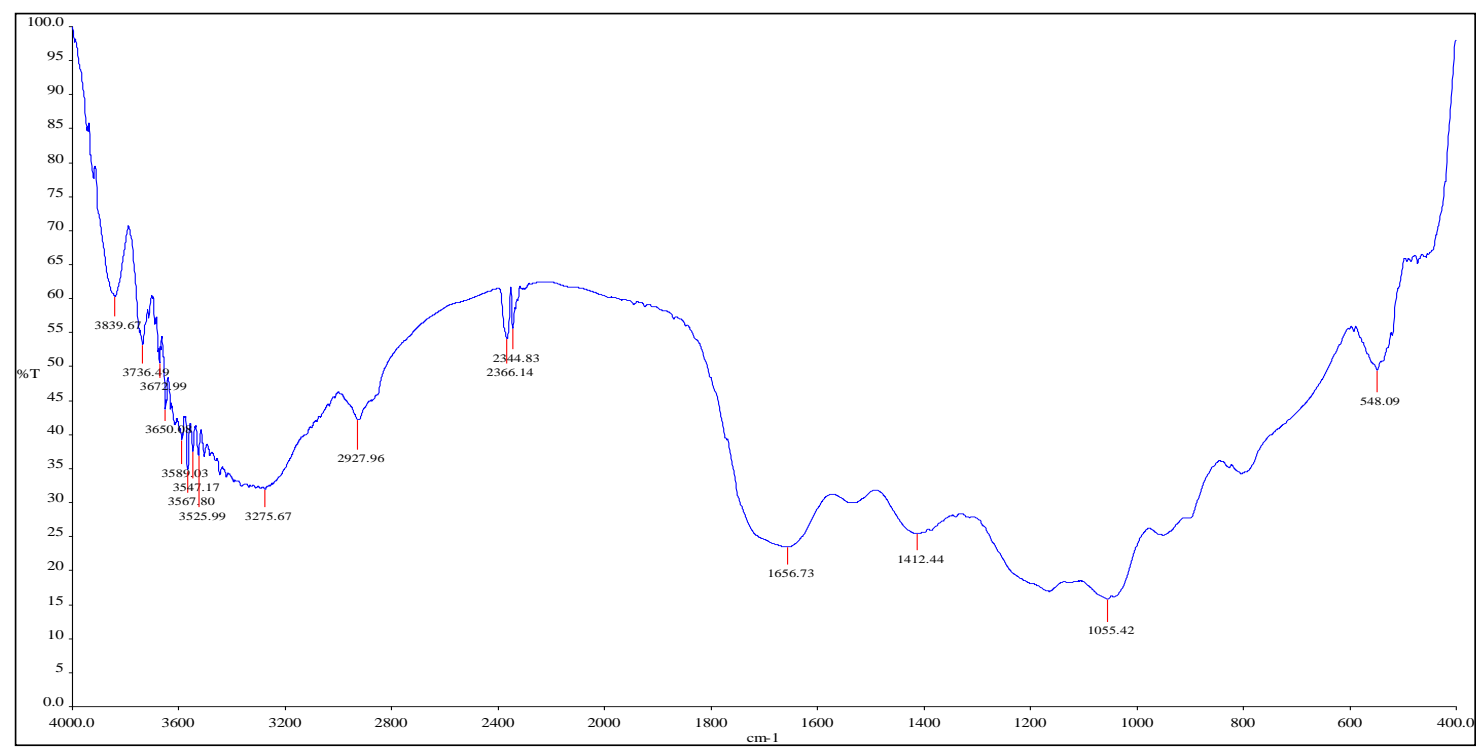

Figure 2: FT-IR spectrum of treated $P$. purpureum.

Table 1: FT-IR spectra comparison between untreated and treated P. purpureum.

\begin{tabular}{|c|c|c|c|c|c|}
\hline \multicolumn{3}{|c|}{ Untreated $P$. purpureum } & \multicolumn{3}{|c|}{ Treated $P$. purpureum } \\
\hline $\begin{array}{l}\text { Wavelength } \\
\left(\mathrm{cm}^{-1}\right)\end{array}$ & $\begin{array}{c}\text { Type of } \\
\text { vibration }\end{array}$ & $\begin{array}{c}\text { Functional } \\
\text { Group }\end{array}$ & $\begin{array}{l}\text { Wavelength } \\
\quad\left(\mathrm{cm}^{-1}\right)\end{array}$ & $\begin{array}{c}\text { Type of } \\
\text { vibration }\end{array}$ & $\begin{array}{l}\text { Functional } \\
\text { Group }\end{array}$ \\
\hline 803.94 & $\begin{array}{l}\mathrm{C}=\mathrm{C} \text { bending, } \\
\mathrm{C}-\mathrm{H} \text { bending }\end{array}$ & $\begin{array}{c}\text { Alkene, } 1,4- \\
\text { disubstituted or } \\
1,2,3,4- \\
\text { tetrasubstituted }\end{array}$ & 1055.42 & $\begin{array}{l}\text { C-O stretch, } \\
\text { C-N stretch, } \\
\mathrm{S}=\mathrm{O} \text { stretch }\end{array}$ & $\begin{array}{c}\text { Primary } \\
\text { alcohol, Vinyl } \\
\text { ether, Amine, } \\
\text { Alkyl aryl ether, } \\
\text { Sulfoxide }\end{array}$ \\
\hline 1054.28 & $\begin{array}{l}\text { C-O stretch, } \\
\text { C-N stretch }\end{array}$ & $\begin{array}{l}\text { Primary alcohol, } \\
\text { Vinyl ether, } \\
\text { Alkyl aryl ether, } \\
\text { Amine }\end{array}$ & 1412.44 & $\mathrm{O}-\mathrm{H}$ bending & $\begin{array}{l}\text { Alcohol, } \\
\text { Carboxylic acid }\end{array}$ \\
\hline 1419.21 & $\begin{array}{l}\mathrm{C}-\mathrm{H} \text { bending, } \\
\mathrm{O}-\mathrm{H} \text { bending }\end{array}$ & $\begin{array}{l}\text { Alkane, Alcohol, } \\
\text { Carboxylic acid }\end{array}$ & 1656.73 & $\begin{array}{l}\mathrm{C}=\mathrm{C} \text { stretch, } \\
\mathrm{C}=\mathrm{N} \text { stretch }\end{array}$ & $\begin{array}{c}\text { Alkene, } \\
\text { Imine/Oxime }\end{array}$ \\
\hline 1644.08 & $\mathrm{C}=\mathrm{N}$ stretch & Imine/oxime & 2927.96 & $\begin{array}{l}\text { C-H stretch, } \\
\text { O-H stretch, } \\
\text { N-H stretch }\end{array}$ & $\begin{array}{c}\text { Alkane, } \\
\text { Carboxylic acid, } \\
\text { Alcohol, Amine } \\
\text { salt }\end{array}$ \\
\hline 2920.51 & -C-H stretch & Alkane & 3275.67 & $\begin{array}{l}\text { O-H stretch, } \\
\text { N-H stretch }\end{array}$ & $\begin{array}{c}\text { Alcohol, } \\
\text { Carboxylic acid, } \\
\text { Aliphatic } \\
\text { primary amine }\end{array}$ \\
\hline 3375.64 & $\mathrm{~N}-\mathrm{H}$ stretch & $\begin{array}{c}\text { Aliphatic } \\
\text { primary amine }\end{array}$ & $\begin{array}{l}3525.99 \\
3547.17\end{array}$ & $\mathrm{O}-\mathrm{H}$ stretch & Alcohol \\
\hline 3572.79 & $\mathrm{O}-\mathrm{H}$ stretch & Alcohol & $\begin{array}{c}3567.80 \\
3589.03 \\
3650.083672 .99 \\
\end{array}$ & & \\
\hline
\end{tabular}




\section{Scanning Electron Microscope (SEM)}

As shown in Figure 3 (a) and (b), the surface of untreated $P$. purpureum was irregular, smooth and compact. The presence of pore and cavities was observed but they posed a close structure. The treatment of $P$. purpureum with $\mathrm{HNO}_{3}$ showed improvement in physical characteristics as shown in Figure 4 (a) and (b). The surface of treated $P$. purpureum was rougher compared to that untreated. The pores and cavities could be easily observed and the pores were in deeper and wider structure, which indicated that the treated $P$. purpureum had more porous structure and provided a better pore size distribution. These characteristics are fundamental for biosorption process since it makes the active sites more accessible. The grooves on the treated biosorbent were formed by removing the impurities on the surface of adsorbent during the nitric acid treatments, which may help to increase the roughness and binding sites on material surface (Wang et al., 2016). The SEM micrographs of $\mathrm{HNO}_{3}$ treated biosorbent also presented the clear removal of a surface layer and empty space between the biosorbent, which indicated the removal of impurities such as higher hemicellulose layer in natural fibres (Kamarullah et al., 2015).

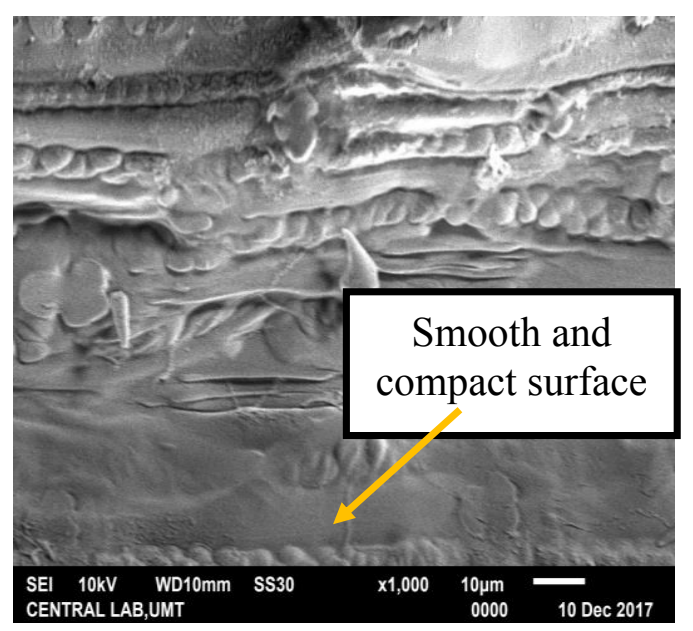

(b)

(a)

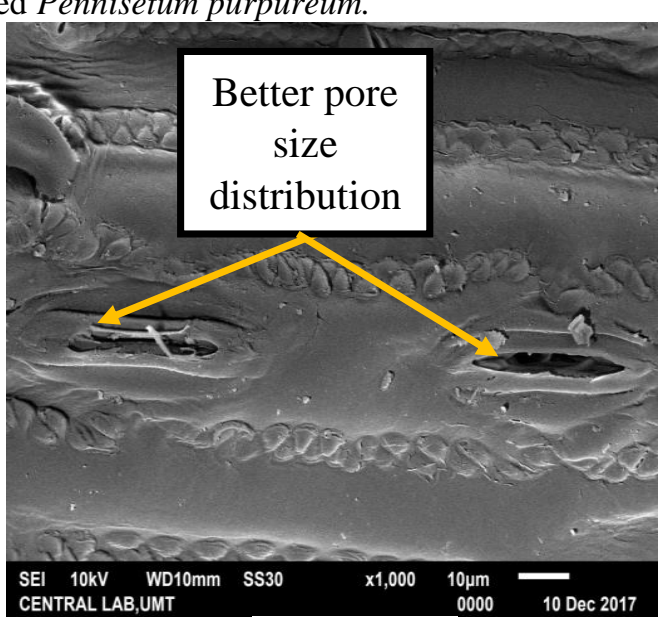

(b)

(a)

Figure 4: SEM micrographs of treated Pennisetum purpureum.

\section{Analysis of Surface Area and Porosity (ASAP)}

The texture properties such as surface area and pore volume play a significant role in sorption process of metal ions (Ciesielczyk et al., 2016). Surface area and pore size distribution of untreated and treated $P$. purpureum were measured using BET (Brunauer-Emmett-Teller) and BJH (Barrett-Joyner-Halenda) analysis. Table 2 shows the summary of BET and BJH analysis results for untreated and treated $P$. purpureum. 
Table 2: BET and BJH analysis results for untreated and treated P. purpureum.

\begin{tabular}{cccc}
\hline Sample & $\begin{array}{c}\text { BET surface area } \\
\left(\mathbf{m}^{2} / \mathbf{g}\right)\end{array}$ & $\begin{array}{c}\text { BJH adsorption } \\
\text { cumulative pore } \\
\text { volume }\left(\mathbf{c m}^{\mathbf{3}} \mathbf{g}\right)\end{array}$ & $\begin{array}{c}\text { BJH adsorption average } \\
\text { pore diameter }(\mathbf{n m})\end{array}$ \\
\hline Untreated P. purpureum & 1.1077 & 0.003752 & 52.6709 \\
Treated $P$. purpureum & 1.3385 & 0.005987 & 27.7506 \\
\hline
\end{tabular}

From Table 2, BET surface area of $P$. purpureum after nitric acid modification showed an increment from 1.1077 $\mathrm{m}^{2} / \mathrm{g}$ to $1.3385 \mathrm{~m}^{2} / \mathrm{g}$, which in turn increased the pore volume of Pennisetum purpureum. This indicates that nitric acid modification on biosorbent enhances the porous characteristics such as surface area, pore volume and better pore size distribution. However, nitric acid modification of $P$. purpureum decreased the $\mathrm{BJH}$ adsorption average pore diameter from $52.6709 \mathrm{~nm}$ (macropores) to $27.7506 \mathrm{~nm}$ (mesopores). Zhu et al. (2017) suggested using mesoporous materials for heavy metals adsorption due to its exceptionally larger surface area, regular pore structure and tunable pore size. Therefore, all these characteristics help to explain the higher adsorption capacity of nitric acid-treated $P$. purpureum compared to untreated $P$. purpureum.

\section{The Effect of $p H$}

The initial $\mathrm{pH}$ of solution is one of the most important parameters which will affect the surface charge of biosorbent and uptake of heavy metals from wastewater (Tumin et al., 2008). Figure 5 shows the graph of percent removal against varing $\mathrm{pH}$. For untreated $P$. purpureum, the uptake of cadmium ions increased from $27.5 \%$ to 92.8\% when the $\mathrm{pH}$ increased from $\mathrm{pH} 1$ to $\mathrm{pH} 4$. Treated
$P$. purpureum also displayed an increase in cadmium ions uptake from $34.1 \%$ to $97.8 \%$ within $\mathrm{pH} 1$ to $\mathrm{pH} 4$. The minimum adsorption value was observed for both biosorbents at $\mathrm{pH} 1$. This is because a highly acidic solution with low $\mathrm{pH}$ can cause the net charge of the active sites on the surface of biosorbent to become positive since it is surrounded by hydronium ions $\left(\mathrm{H}^{+}\right)$(Wong et al., 2003). Therefore, the reduction in the number of negatively charged sites prevented the adsorption of positively charged cadmium ions on the surface of biosorbent.

In contrast, more negatively charged sites become available when the $\mathrm{pH}$ of solution increases. As the $\mathrm{pH}$ increases, the functional groups of biosorbent become deprotonated and are more accessible for the attraction of metal ions, thus increase the adsorption of metal cations (Anayurt et al., 2009). Both untreated and treated $P$. purpureum showed a slight decrease in percent removal at

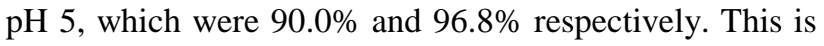
due to the occurrence of cadmium precipitation (Tumin et al., 2008). At this stage, the $\mathrm{Cd}(\mathrm{OH})^{+}$and $\mathrm{Cd}(\mathrm{OH})_{2}$ are present in large quantities compared to $\mathrm{Cd}^{2+}$, which affect the adsorption of $\mathrm{Cd}^{2+}$. Hence, the result demonstrated that the best $\mathrm{pH}$ for both biosorbents in adsorption of cadmium ions is $\mathrm{pH} 4$.

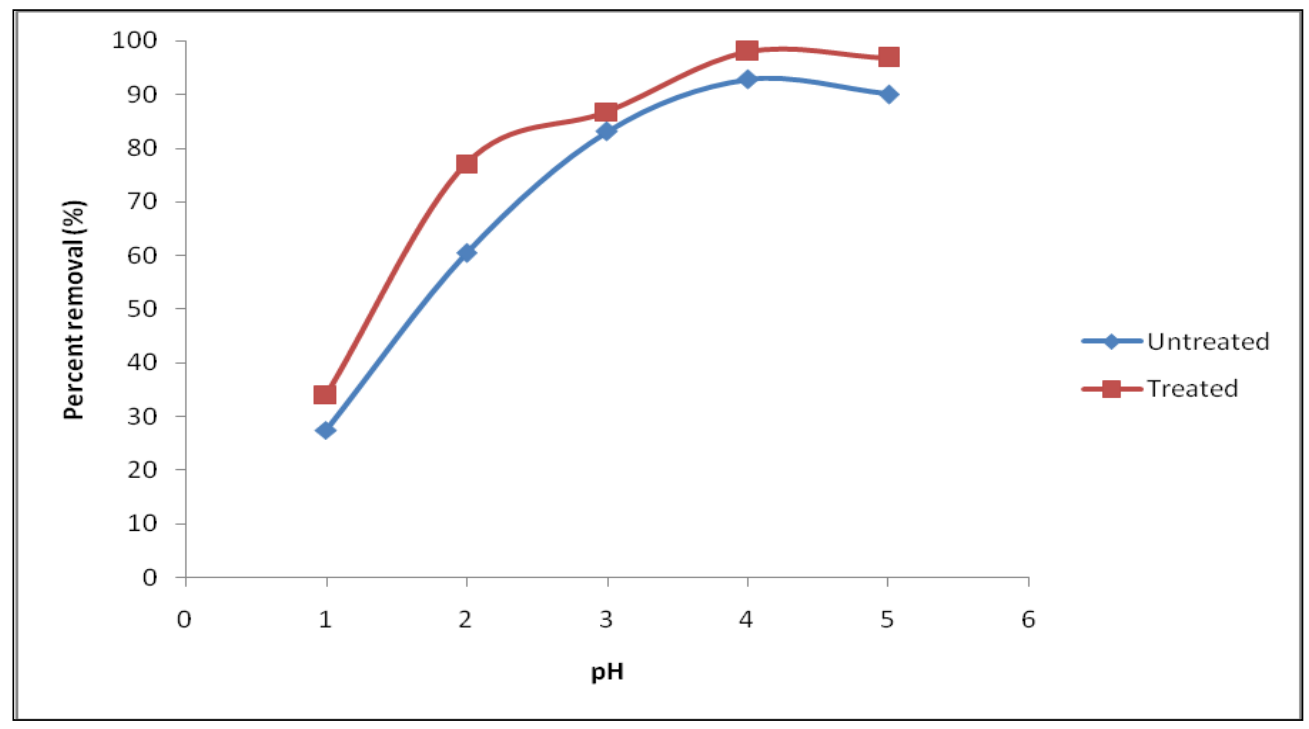

Figure 5: The effect of $\mathrm{pH}$ on the adsorption of $\mathrm{Cd}(\mathrm{II})$ ions. 


\section{The Effect of Initial Metal Ion Concentration}

The initial metal ion concentration determines the amount of metal ion biosorbed in the condition when there are available binding sites. Figure 6 shows the result of the effect of initial metal ion concentration on the uptake of cadmium ions. Based on the result obtained, the removal rate increased from $63.3 \%$ and $74.8 \%$ at $5 \mathrm{mg} / \mathrm{L}$ to $92.3 \%$ and $97.4 \%$ at $25 \mathrm{mg} / \mathrm{L}$ for both untreated and treated $P$. purpureum respectively. This is due to the higher initial concentration that leads to a higher affinity of metal ions towards active sites (Al-Asheh et al., 2003). The higher initial metal ion concentration also indicates the higher availability of metal ions for adsorption. Therefore, the collision between cadmium ions and the biosorbent increases, which in turn increases the rate of reactions, causing the removal rate to increase.

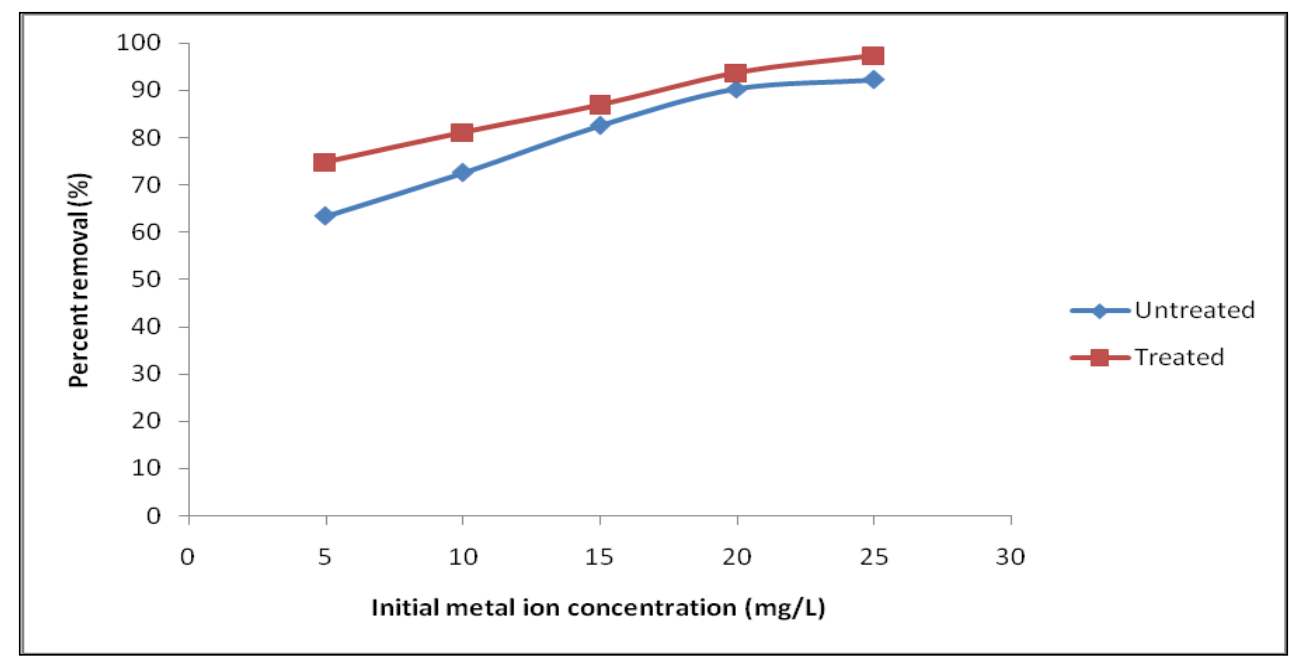

Figure 6: The effect of initial metal ion concentration on the adsorption of $\mathrm{Cd}(\mathrm{II})$ ions.

\section{The Effect of Contact Time}

Figure 7 displays the effect of contact time onto the biosorption of cadmium ions. The biosorption of both untreated and treated $P$. purpureum increased rapidly within the first 30 minutes. Therefore, 30 minutes was taken as the best contact time. It is important to note that the adsorption of cadmium ions proceeded in 2 stages for both biosorbents. At the first stage which lasted for 30 minutes, the maximum removal rate was $96.3 \%$ and $97.0 \%$ for both untreated and treated $P$. purpureum respectively. This can be explained by the availability of all the active sites on the surface of biosorbent (Rao et al., 2010). In the second stage, the removal rate of cadmium ions slightly decreased and achieved equilibrium. This indicates that the rate of biosorption slows down due to the adsorption of cadmium ions that blocks the pores and uses up the available binding sites on the surface of biosorbent (Babarinde \& Babalola, 2010). 


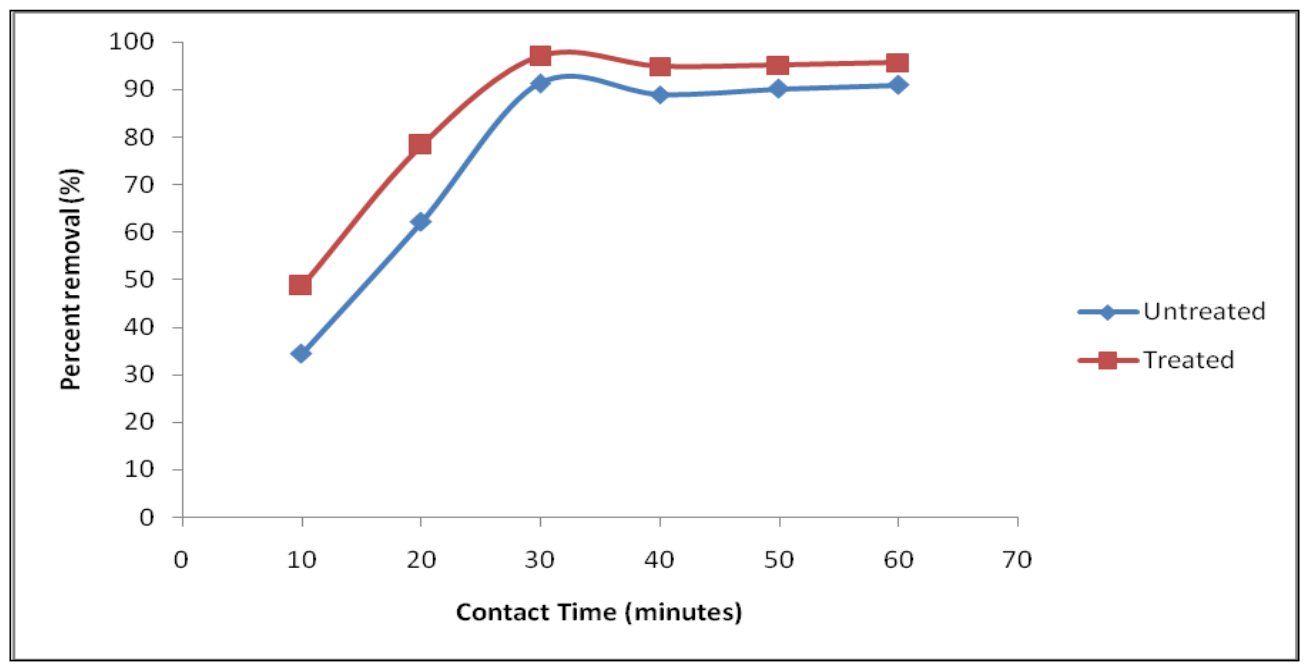

Figure 7: The effect of contact time on the adsorption of Cd (II) ions

\section{The Effect of Adsorbent Dosage}

The adsorbent dosage is another important parameter which affects the biosorption of metal cations. Figure 8 shows the effect of adsorbent dosage on the percent removal of cadmium ions from aqueous solution. The trend of the graph demonstrated that the metal uptake increased from $21.3 \%$ and $29.8 \%$ with $0.2 \mathrm{~g}$ of adsorbent up to $86.5 \%$ and $97.3 \%$ with $0.6 \mathrm{~g}$ of adsorbent for both untreated and treated $P$. purpureum respectively. This is due to limited amount of cadmium ions present in aqueous solution exposed to a larger amount of active sites at higher adsorbent dosage, which can achieve a high adsorption percentage at appropriate dosage (Babel \& Kurniawan, 2004). Therefore, $0.6 \mathrm{~g}$ of adsorbent is considered as the best adsorbent dosage for cadmium ions removal. However, the adsorption percentage decreased sharply with an increase in adsorbent dosage after $0.6 \mathrm{~g}$. This is due to the presence of excessive amount of adsorbent causing the overcrowding of adsorbent particles, and hence overlapping the active sites and make it unavailable for adsorption of cadmium ions (Garg et al., 2003). Besides that, high amount of adsorbent dosage would impose a screening effect on the surface of adsorbent, thereby shielding the active sites from the adsorption of metal ions (Tumin et al., 2008).

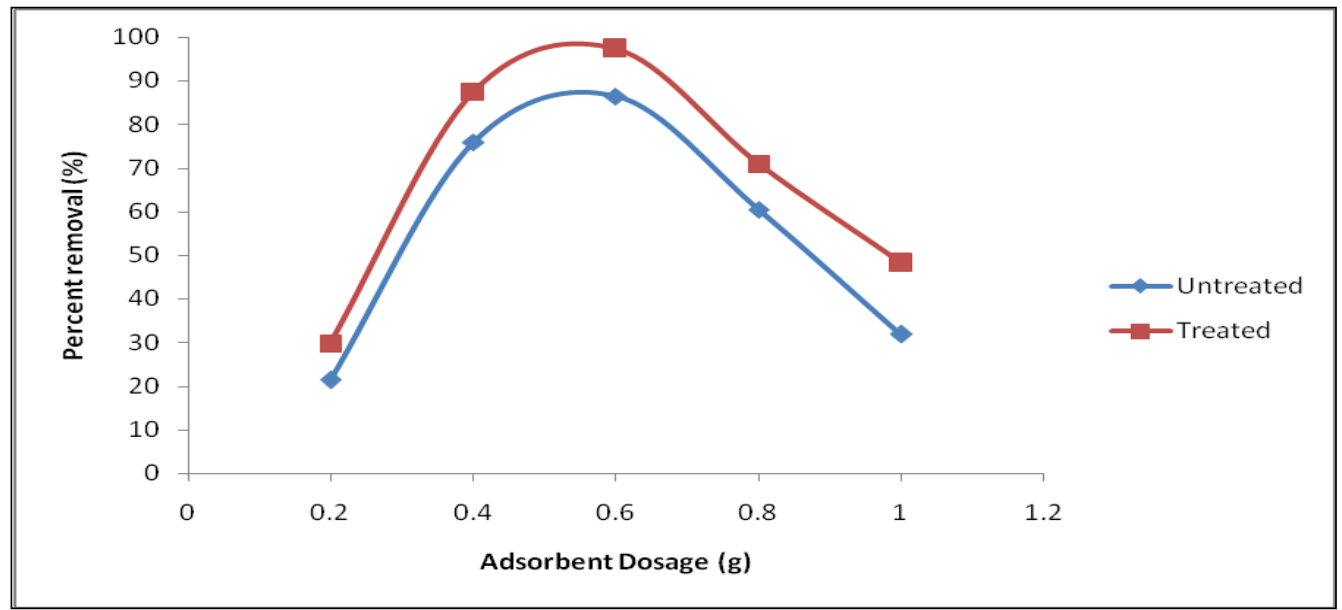

Figure 8: The effect of adsorbent dosage on the adsorption of Cd(II) ions.

\section{Conclusion}

This study has investigated the potential of $P$. purpureum as low cost biosorbent for cadmium ions removal. As a conclusion, the derivation of $P$. purpureum as a low cost biosorbent is an ideal way to replace commercial activated carbon for treating metal ions present in wastewater. The FT-IR analysis indicated that the functional groups for both biosorbents consist of carbonyl, carboxyl, hydroxyl and amine groups which are able to bind with the positively charged cadmium ions. The presence of these functional groups mainly contribute to ion exchange, physical 
adsorption, electrostatic attraction and complexation mechanisms.

SEM micrographs have shown that untreated $P$. purpureum had irregular, smooth and compact surface. After the nitric acid treatment, it showed an improvement in physical characteristics such as deep, open pores and better pore size distribution by removing the impurities on the surface of biosorbent, which may help to increase the roughness and make the active sites more accessible. The ASAP analysis revealed that the surface area and pore volume of treated $P$. purpureum $\left(1.3385 \mathrm{~m}^{2} / \mathrm{g}\right.$ and $0.005987 \mathrm{~cm}^{3} / \mathrm{g}$ respectively) were larger than untreated $P$. purpureum $\left(1.1077 \quad \mathrm{~m}^{2} / \mathrm{g}\right.$ and $0.003752 \quad \mathrm{~cm}^{3} / \mathrm{g}$ respectively). However, nitric acid modification of $P$. purpureum decreased the pore diameter from macropores

\section{Acknowledgements}

The author would like to express appreciation to the School of Ocean Engineering, Universiti Malaysia Terengganu for provision of research facilities and technical supports throughout the execution of this final year project.

\section{References}

Al-Asheh, Banat, R., Al-Omari, Z. \& Duvnjak, (2003). Beneficial reuse of chicken feathers in removal of heavy metals from wastewater. Cleaner Production, 11, 321-326.

Anayurt, R.A., Sari, A., \& Tuzen, M. (2009). Equilibrium, Thermodynamic and Kinetic Studies on Biosorption of $\mathrm{Pb}$ (II) and $\mathrm{Cd}(\mathrm{II})$ from Aqueous Solution by Macrofungus (Lactarius scrobiculatus) Biomass. Chemical Engineering Journal, 151, 255 - 261.

Babarinde, N. A. A. \& Babalola, J. O. (2010). The biosorption of $\mathrm{Pb}(\mathrm{II})$ from solution by elephant grass (pennisetum purpureum): Kinetic, equilibrium, and thermodynamic studies. The Pacific Journal of Science and Technology, 11 (1).

Babel, S. \& Kurniawan T. A. (2004). Cr (VI) removal from synthetic wastewater using coconut shell charcoal and commercial activated carbon modified with oxidizing agents and/or chitosan. Chemosphere. 54 (7), 951 67.

Barakat, M. A. (2011). New trends in removing heavy metals from industrial wastewater. Arabian Journal of Chemistry, 4 (4), 361 - 377.
$(52.6709 \mathrm{~nm})$ to mesopores $(27.7506 \mathrm{~nm})$. It is suggested that mesoporous materials are preferable for adsorption of heavy metals due to their exceptionally larger surface area, regular pore structure and tunable pore size.

Moreover, the best conditions were obtained from the batch adsorption experiments. For both untreated and treated Pennisetum purpureum, the best $\mathrm{pH}$, contact time and adsorbent dosage were determined at $\mathrm{pH} 4,30$ minutes and $0.6 \mathrm{~g}$, respectively. In addition, the initial metal ion concentration had specific influence on the final removal percentage of $\mathrm{Cd}$ (II) ions. It was found that the Cd (II) percent removal was directly proportional to the initial metal ion concentration. The highest Cd (II) ion removal achieved using untreated $P$. purpureum was $92 \%$ while the nitric acid-treated $P$. purpureum exhibited $98 \%$ removal.

Ciesielczyk, F., Bartczak, P. \& Jesionowski, T. (2016). Removal of cadmium (II) and lead(II) ions from model aqueous solutions using sol-gel derived inorganic oxide adsorbent. Springer, 22, $445-458$.

Garg, V. K., Gupta, R., Yadav, A. B. \& Kumar, R. (2003). Dye removal from aqueous solution by adsorption on treated sawdust. Bioresource Technology. 89, 121 124.

Hong, F., Jin, T. \& Zhang, A. (2004). Risk assessment on renal dysfunction caused by co-exposure to arsenic and cadmium using benchmark dose calculation in a Chinese population. Biometals. 17, 573-580.

IARC (1993). Lyon IARC Monographs on the Evaluation of Carcinogenic Risks to Humans. International Agency for Research on Cancer, 148-161, 206-210.

Javanbakht, V., Alavi, S. A. \& Zilouei, H. (2014). Mechanisms of heavy metal removal using microorganisms as biosorbent. Water Science \& Technolog,. 69 (9), 1775 - 1787.

Kamarullah, S. H., Mydin, M. M., Omar, W. S. A. W., Harith, S. S., Noor, B. H. M., Alias, N. Z. A., Manap, S. \& Mohamad, R. (2015). Surface Morphology and Chemical Composition of Napier Grass Fibers. Malaysian Journal of Analytical Sciences, 19 (4), 889 -895 .

Koyu, A., Gokcimen, A., Ozguner, F., Bayram, D.S., Kocak, A. (2006). Evaluation of the effects of cadmium on rat liver. Molecular Cell. Biochemistry, $284,81-85$.

Qiao, X., Huang, W. \& Bian, Y. (2014). Effective removal of cadmium ions from a simulated gastrointestinal fluid by Lentinus edodes. International Journal of 
Environmental Research and Public Health, 11 (2), $12486-12498$.

Raja, P., Veerasingam, S., Suresh, G., Marichamy, G. \& Venkatachalapathy, R. (2009). Heavy metals concentration in four commercially valuable marine edible fish species from Parangipettai Coast, South East Coast of India. International Journal of Animal and Veterinary Advances. 1 (1), 10 - 14.

Rao, K. S., Mohapatra, M., Anand, S. \& Venkateswarlu, P. (2010). Review on cadmium removal from aqueous solution. International Journal of Engineering Science and Technology. 2, $81-103$.

Raoul, T. T. D., Angwafor, N. G. N., Christian, N. S., Theopile, K., Manga, N. H., Gabche, A. S. \& Mbadcam, K. J. (2016). Optimization of Cadmium (II) Adsorption onto Modified and Unmodified Lignocellulosics (Rice Husk and Egussi Peeling). International Journal of Basic and Applied Sciences. 5 (1), $45-51$.

Tellez-Plaza, M., Navas-Acien, A., Crainiceanu, C. M. \& Guallar, E. (2008). Cadmium exposure and hypertension in the 1999-2004 National Health and Nutrition Examination Survey (NHANES). Environmental Health Perspective, 116, 51-56.

Tumin, N. D., Chuah, A. L., Zawani, Z. \& Rashid, S. A. (2008). Adsorption of copper from aqueous solution by Elais guineensis kernel activated carbon. Journal of Engineering Science and Technology. 3 (2), 180 189.

Ullah, M. R. \& Haque, M. E. (2010). Spectrophotometric Determination of Toxic Elements (Cadmium) in Aqueous Media. Journal of Chemical Engineering, IEB. 25 (1).

Venkatesan, G. \& Senthilnathan, U. (2013). Adsorption Batch Studies on the Removal of Cadmium using Wood of Derris Indica based Activated Carbon. Research Journal of Chemistry and Environment. 17 (5).

Wang, L., Liu, N., Guo, Z., Wu, D., Chen, W., Chang, Z., Yuan, Q., Hui, M. \& Wang, J. (2016). Nitric AcidTreated Carbon Fibers with Enhanced Hydrophilicity for Candida tropicalis Immobilization in Xylitol Fermentation. Materials. 9 (206).

Wong, K. K., Lee, C. K., Low, K. S. \& Haron, M. J. (2003). Removal of $\mathrm{Cu}$ and $\mathrm{Pb}$ by tartaric acid modified rice husk from aqueous

Chemosphere. 50, 23 - 28.

Solutions.

Zhu, W. J., Wang, J. X., Wu, D., Li, X., Luo, Y., Han, C., Ma, W. \& He, S. (2017). Investigating the heavy metal adsorption of mesoporous silica materials prepared by microwave synthesis. Nanoscale Research Letters, 12(1), 323. 